\title{
Influence of abiotic factors on the green mass and seed productivity of the raw material of Levisticum officinale c. Koch in the conditions of Transcarpathia
}

\author{
Kormosh, S. M. ${ }^{1}$, Simon, G. ${ }^{2}$ \& Povlin, I. E. ${ }^{3}$ \\ ${ }^{I}$ Transcarpathian State Agricultural Experimental Station of The National Academy of Agricultural Sciences of Ukraine \\ ${ }^{2}$ Szent István University, Faculty of Horticultural Science, Hungary \\ ${ }^{3}$ Ferenc Rákóczi II Transcarpathian Hungarian Institute, Ukraine \\ Author for correspondence: simon.gergely@kertk.szie.hu
}

\begin{abstract}
Summary: For the wide implementation of Levisticum officinale C. Koch in Transcarpathia into production it is necessary to widen its sort composition, as it is rather poor in Ukraine. Solving this problem is possible by enriching the source material with the samples of different ecological and/or geographical origin, by studying the influence of abiotic factors on the formation of green mass and seed productivity, separating the specimens best adapted to the conditions of growing, involving them into the selection process and creating new, highly productive sorts on this basis. The scientists of the Transcarpathian State Agricultural Experimental Station (TSAES) conducted researches (during 2011-2016) on the adaptive potential of the source material of the type of Levisticum officinale C. Koch, which counts seven samples (Ukraine - 5 samples, Poland - 1, and Romania - 1), the selection work on creating new varieties for the given region is being done. The investigations were made on soddy podzolic gleyed low-humus soils with low content of nutrients. The results were obtained on the basis of generally accepted methods of investigation, i.e.: laboratory, field, visual, measuring-weighing, biochemical, mathematically statistic, and comparative-calculating. In the conditions of Transcarpathia the spicy greens of the high quality L. officinale C. Koch are being gathered on days 25-30, the output of the essential oil makes up from 0.72 to $1.89 \%$ on c.d.s., depending on the climate conditions of growing. The plants pass through all the stages of development, the bush is 55.4 to $92.7 \mathrm{~cm}$ in height, the plants form a big amount of rosette-shaped stems (11-34 pieces), the productivity of spicy greens is between 9.9 and $42.1 \mathrm{t}$ ha ${ }^{1}$. The scientists of TSAES created the following sorts - Mriya (A. c. 06131 Ukraine, first registered in the State register of plant varieties of Ukraine) and Coral (Pat. on the variety № 140830). Economic effect from growing of the Coral variety in the conditions of Transcarpathia is 10230 UAH/ha and the level of profitability is $28.4 \%$. The geographic position and agroclimatic conditions of Transcarpathia, as well as the unpretentiousness of $L$. officinale C. Koch. to the conditions of growing contribute to the enrichment of the local flora with useful plants; and the rich chemical composition contributes to the spread of this culture in the given region.
\end{abstract}

Kormosh, S. M., Simon, G., Povlin, I. E. (2019): Influence of abiotic factors on the green mass and seed productivity of the raw material of Levisticum officinale c. Koch in the conditions of Transcarpathia. International Journal of Horticultural Science 25(1-2): 46-51. https://doi.org/10.31421/IJHS/25/1-2/2951

Key words: Levisticum officinale, enrichment, productivity, seeds, abiotic, crops, essential oil, spice, variety, profitability

\section{Introduction}

The unmanaged human activity has led to the partial or full disappearance of many species of plants. Therefore the question of enriching and introduction of the useful and new plants into the culture in each separate region became crucial.

Transcarpathian region is a special region where a set of specific factors is combined, namely it is land poor, the majority of soils is hard, sour and has low humus content, but the climate conditions of the region are extremely preferable for industrial growing of such useful plants that are relatively rare in the Carpathian region as Levisticum officinale C. Koch, Ocimum L., Lophanthus anisatus Benth., Leonurus guinguelobatus Gilib., Capsicum annum L. convar. longum DC (Rakhmetov, 2016; Cherevchenko, 2012; Derzhipilskiy, 2006). They can take a worthy place in the production of goods with an original flavor for the food and canning industry and serve as raw material for other branches of production. (Korablyova, 2012; Nazarenko, 2008). These types of aromatic plants are especially valuable for the regions with low quality soil, such as Transcarpathia because they are unpretentious to the growing conditions and can grow on the lands unadapted for growing other valuable agricultural greens.

Fast development of social infrastructure (recycling and canned food production, health resorts, green tourism development, recreation centers) of the Transcarpathian region and favorable agro-climatic conditions of the region can serve for the creation of the region's own raw material basis of aromatic plants for pharmaceutical and food industry. As Levisticum officinale $\mathrm{C}$. Koch is considered to be one of the best spicy and medicinal plants, that is why each year the interest towards it rises as well (Internet 1).

However, to meet the needs of a producer of green aromatic vegetable raw material regarding competitive, highly productive sorts it is necessary to have them in the sufficient amount; and this does not occur nowadays. The main reason of the impossibility to put the production of lovage on the industrial scale is the lack of information on its biological and morphological peculiarities, the insufficient amount of studies of its valuable characteristics, and the absence of the adaptive 
selection material and varieties, insufficient knowledge of the technological peculiarities of growing this culture.

The global climate changes, essential increase of the amplitude of fluctuation of meteorological factors, their reorganization and subdivision according to the locations sometimes leads to the loss of the productive raw material of lovage and this creates the necessity of new approaches to the creation of new genetic types of this culture that have a minimal reaction to the extreme climate changes (Sichkar et al., 2013). Ecological, environmental factors and their complex interaction are essential components of the growth and development of plants, the productivity of green mass and seeds. Raw and high quality seeds can only be obtained at the optimal level of all environmental factors. The issue of determining the influence of weather conditions in different phases of growth and development of plants, which in the future have a significant impact on the formation of biomass and seeds is particularly important. The limiting factors, which are temperature and the amount of precipitation, significantly affect both the formation of biomass and seeds on the parent plant, as well as the development of the future plants. They influence the intensity and direction of differentiation of the generative organs, which in the future determine the formation of seedlings and the different types of their structure (Zhuchenko, 1988).

The essential contribution to the study on the issue of the influence of abiotic factors on agricultural plants was made by such scientists, as Azzi (1959) and Brounov (1957). They identified the critical periods of growth and development of the main cereals and legumes, when the plants are more susceptible to lack or excess moisture and variations in average daily temperatures. Ludilov (1987) indicates the optimal conditions for the formation of pepper seeds: the sum of active temperatures in the period from sowing to sprouting should reach $230-260{ }^{\circ} \mathrm{C}$, from the sprouting to the blooming of the fast ripening varieties $-2200-2300{ }^{\circ} \mathrm{C}$, medium-ripening 2300-2400 ${ }^{\circ} \mathrm{C}$, and $2500{ }^{\circ} \mathrm{C}$ for the late-ripening ones. In the period from planting the seedlings up to the full biological ripeness of the seeds the sum of the active temperatures has to be between $3200-3600{ }^{\circ} \mathrm{C}$, and pepper needs the most moisture during the germination of seeds and transplanting of the seedlings to the permanent place (pepper plants almost completely lose their sucktion roots). Lack of moisture in the soil and air leads to a slower plant growth, and - as a consequence - a decrease in the number of buds, flowers and ovaries on the plant, reducing the yield of fruits (small and deformed fruits are being formed in small quantity).

A number of scholars (Dragavtzev \& Averianova, 1983; Orliyk \& Goncharova, 2003; Bodmer, 1962; Lu \& Chiu, 1976; Allard, 1963) draw special attention to the search of contrast forms with increased abiotic adaptive features able to solve the issue of providing the selection process with samples that possess high variability of productivity features.

Proceeding from the above mentioned, selection posits new tasks among which the main one is the creation of highly adaptive varieties and hybrids of agro-ecological orientation with a high degree of genetic protection of the crop from the variable environmental factors. Conducting research in different geographical and ecological conditions makes it possible to determine the degree of adaptability of the genotype to the environment of a specific zone in terms of variability of the main features. Since it is known that valuable characteristics of a plant variety depend not only on hereditary genetic properties, but on the influence of the environmental factors as well.

The important characteristics of the plants are the followings: adaptive ability, the growth, the development of the plant and of the constant high productivity in the strictly defined agro-climatic conditions, independent from the changing biotic and abiotic factors. We should mention that no detailed study of the influence of abiotic factors on the formation of the productivity of both the green mass and the seeds of Levisticum officinale C. Koch has been conducted in Ukraine. That is why the issues, that are being discussed in this paper are topical and extremely important today, especially for Ukraine, where this culture is rare and the obtained knowledge will allow to elaborate the methods of improving the quality of the raw material and seeds in the process of their formation, handling and preserving.

The task of the research for the scientific workers of TSAES is to find out the influence of the ecological factors on the formation of green mass and seed productivity and its crops and to single out the forms that are resistant to the changing agro-ecological factors in order to involve them into the selection process.

\section{Materials and methods}

The research was conducted in open soil on the fields of TSAES NAAS during the years 2011-2016. The material for the investigation consisted of 7 selection samples of lovage (including two sorts of foreign selection and two of domestic and local forms). The obtained results were compared with the generally accepted standard in Ukraine: the 'Mriya' variety (first included in the State Register of plant varieties of Ukraine in 2008). The evaluation of selection varieties was carried out according to the productivity of green mass and seeds, depending on the limiting factors of the conditions of cultivation.

Selection work was carried out in accordance with the methodological recommendations of the leading scientific institutions of Ukraine, the description of the plants created according to the classification of characteristics developed by Kormosh \& Leonova (2007). The statistical processing of the research results was carried out using the method of dispersion analysis according to the methodological recommendations and with the computer programs "Statistik" and "Statistik-6" (Dospekhov, 1985).

\section{Results and discussion}

The most prominent indicator of the adaptive ability and ecologic flexibility of agricultural crops including lovage is the productivity of the high quality raw material. The harvest is the final result of the plant's life processes during the growing season and its interaction with the external environment. The degree of detection of the productivity potential is determined by genetic information that is contained in the plant and the conditions of the environment in which it is grown. A dynamic approach to the study of yield capacity includes monitoring and analysis of the dynamics of plant development at all phases of phenology, the study of the habitus of the plant, the accumulation of dry matter and biologically active components, the determination of resistance to drought, high and low temperatures, diseases and pests. All these factors affect the formation of ground mass and seeds. 
We should mention that in the conditions of the lowlands of Transcarpathia lovage is a cold- and drought-resistant plant, which begins to grow in the end of March or beginning of April and forms a significant amount of biomass after 35-40 days of growing, regardless of the growing conditions, which is shown in Table 1.

Table 1. Dependence of the lovage green mass productivity on the sum of active temperatures and precipitation during the vegetation periods in 2011-2016.

\begin{tabular}{|c|c|c|c|c|c|}
\hline Year & $\begin{array}{c}\text { Sum of } \\
\text { active } \\
\text { temperatures } \\
\left({ }^{\circ} \mathrm{C}\right)\end{array}$ & $\begin{array}{l}\text { Amount of } \\
\text { precipitation } \\
(\mathrm{mm})\end{array}$ & $\begin{array}{c}\text { HTC } \\
(\mathrm{X})\end{array}$ & $\begin{array}{c}\text { Crop } \\
\text { productivity, } \\
\mathrm{t} \mathrm{ha}^{-1} \text { (fact.) } \\
\text { (Y) }\end{array}$ & $\begin{array}{l}\text { Productivity, } \\
\text { t ha }^{-1} \text { (ret.) } \\
\text { (Y) }\end{array}$ \\
\hline 2011 & 3543 & 311.2 & 0.88 & 23.30 & 21.36 \\
\hline 2012 & 3568 & 212.8 & 0.60 & 23.66 & 23.20 \\
\hline 2013 & 3363 & 270.8 & 0.81 & 33.82 & 30.07 \\
\hline 2014 & 3211 & 281.6 & 0.88 & 11.02 & 21.56 \\
\hline 2015 & 3501 & 186.0 & 0.53 & 10.88 & 11.42 \\
\hline 2016 & 3451 & 317.3 & 0.92 & 18.84 & 13.91 \\
\hline average & 3440 & 263 & 0.77 & 20.25 & 20.25 \\
\hline waste & 133.60 & 53.15 & 0.16 & 8.72 & 6.73 \\
\hline $\mathrm{V} \%$ & 3.88 & 20.19 & 21.31 & 43.05 & 33.21 \\
\hline
\end{tabular}

During the years the lovage green mass productivity considerably varied from 10.88 to $33.82 \mathrm{t} \mathrm{ha}^{-1}$ and the coefficient of variation reached $43.05 \%$. The sum of the active temperatures insufficiently influences the formation of the yield of raw materials (Figure 1), and variation coefficient makes up $3.88 \%$.

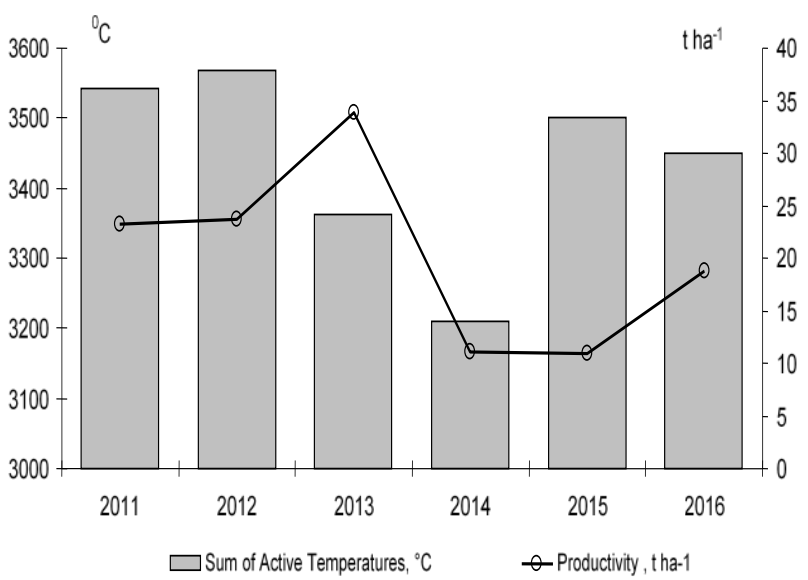

Figure 1. Influence of SAT on lovage productivity during the years 2011-2016.

By analyzing the samples of the lovage source material according to the productivity we have established that there is a low correlation between the productivity and sum of active temperatures $(\mathrm{r}=0.21)$.

The amount of precipitation during the vegetation period has a more significant influence on the formation of lovage biomass and the variation coefficient reaches $20.19 \%$ (Figure 2).

The phenotypic correlation, which is conditioned by the influence of the environmental factors is changeable, thus, the concrete correlation can be useful while choosing the parental pairs for cross-pollination.

Nowadays there is little information concerning the correlation between the characteristics of lovage, but at the same time it is often contradictory.

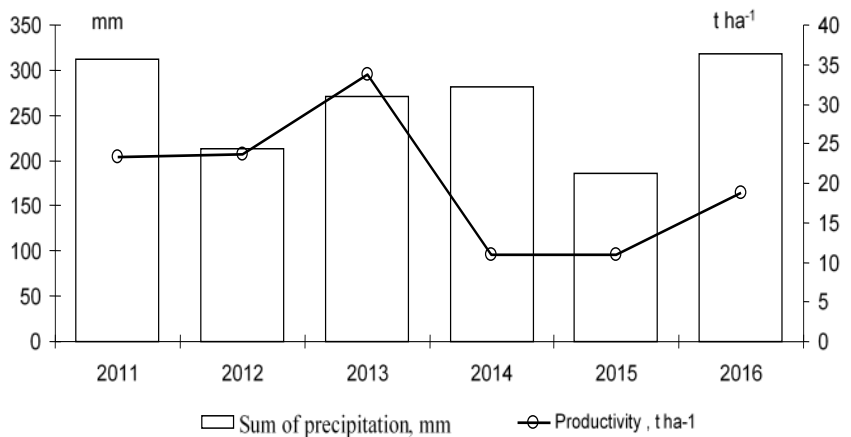

Figure 2. Productive raw material yield depending on the amount of precipitation

It was found correlative dependence between the amount of precipitation and productivity of lovage green mass, which is insufficient; the correlation coefficient makes up $r=0.23$. So, according to the results of our investigations, we can state that the meteorological conditions separately don't have an essential influence on lovage green mass formation. However, precipitation and temperature altogether influence the biomass output. We have established the close correlation between the hydrothermal coefficient (HTC) and productivity $(r=0.77)$ and the variation coefficient $\mathrm{V}$ is essential - it reaches $21.31 \%$. The overall influence of temperature and precipitation (HTC) is defined by the equation: $\mathrm{Y}=-255.7291+789.6903 * \mathrm{x}-$ $539.9197 * \mathrm{x}^{\wedge} 2$ and is shown on Figure 3.

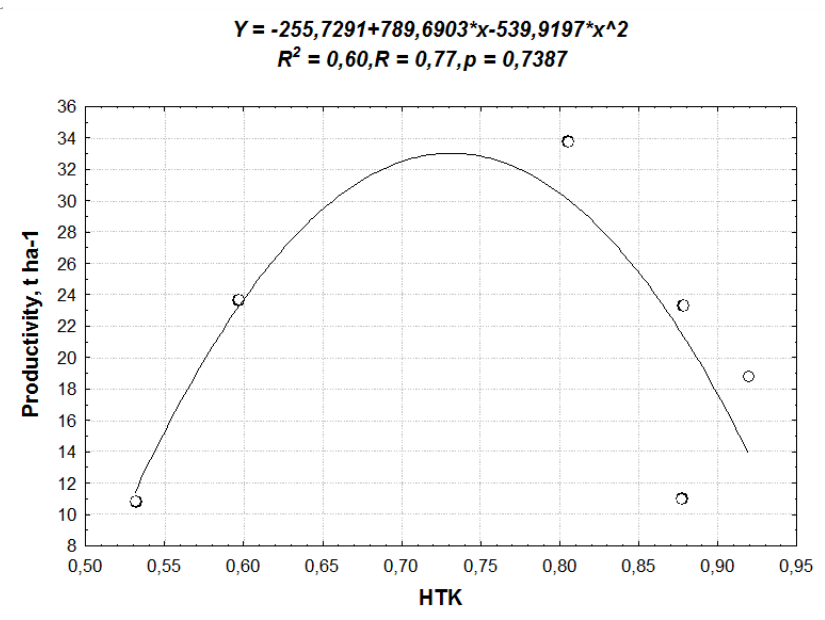

Figure 3. Dependence of lovage green mass productivity on the hydrothermal coefficient (2011-2016)

The determination coefficient is considerable $\left(\mathrm{R}^{2}=0.60\right)$, and the coefficient of the multiple correlation is high $(\mathrm{R}=0.77)$, which indicates the high percentage of possibility of the use of the given equation for the determination of the productivity level.

As it was mentioned above, the formation of the green mass productivity is influenced by the important role of the genotype characteristics and peculiarities of the samples, however, we can't disregard the joint influence of the temperature and precipitation during the vegetation period. The biological potential of lovage biomass formation is high. The green mass productivity varied from 248.0 (K-3, 2015) g to 1053.5 (MLL, 2013) g from a single plant. During the six years of research the biomass productivity fluctuated between 12.5 (Coral) to 30.8 (MLL) $\mathrm{t} \mathrm{ha}^{-1}$. Economically profitable for growing are the samples of lovage with the mass of the plants not less than 
200.0-324.3 g during the first mowing and an output of the commodity raw materials not less than $50-56 \%$.

On average, during the six years, the samples of the source material of lovage exceed these indicators, except for the sample of Coral, the biomass output of which was on the level of $312.3 \mathrm{~g}$. According to the given characteristics the following samples are the best: MLL $-512.3 \mathrm{~g}$ (productivity reaches 28.3 $\mathrm{t} \mathrm{ha}^{-1}$ ) and 56.0\%, Redei $-503.0 \mathrm{~g}$ (correspondingly $-27.9 \mathrm{t} \mathrm{ha}$ ${ }^{1}$ ) and $52.8 \%, \mathrm{~K}-3-493.8 \mathrm{~g}$ (productivity $-27.3 \mathrm{t} \mathrm{ha}^{-1}$ ) and $51.1 \%$.

The results obtained from the lovage samples show that the productivity of the varieties varies considerably in the same ecological conditions, which was on the level $1.4-3.0 \mathrm{~kg} \mathrm{~m}^{-2}$ (from $12.5 \mathrm{t} \mathrm{ha}^{-1}$ to $30.8 \mathrm{t} \mathrm{ha}^{-1}$ ). Statistic calculations show that with such an interval of yield data the best the interval of subdivision is $4.5 \mathrm{t} \mathrm{ha}^{-1}$ (Table 2).

By analyzing data in Table 3. the following varieties react to the changes of the ecological factors of the environment less than the others: Lovage - the indicator of the ecological flexibility coefficient is close to $0\left(b_{i}=0.23\right.$ (green mass output per plant) and $b_{i}=0.24$ (productivity), and variation coefficient with the negative indicator $\left(\mathrm{V}_{\mathrm{i}}=-50.95 \mathrm{i} \mathrm{V}_{\mathrm{i}}=-2.04\right)$, sample MLL $-b_{i}=0.31$ and $V_{i}=-39.69$ and -1.58. Similar data is shown for the indicators of ecological flexibility of the varieties Mriya $\left(b_{i}=0.40\right.$ and $V_{i}=-36.12$ and -1.44$)$ and Coral $\left(b_{i}=0.43\right.$ and $V_{i}=-$ 27.99 and -1.11 , which means that in these samples the characteristics of the green mass per plant and productivity are stable and the influence of meteorological conditions is insufficient.

Table 2. Division of lovage samples according to productivity (years 2011-2016)

\begin{tabular}{|l|c|c|}
\hline No. & Gradation & Variety \\
\hline 1. & $\begin{array}{r}\text { (LP) low productive }- \\
12.0-16.5 \mathrm{tha}^{-1}\end{array}$ & Coral, KJ* \\
\hline 2. & $\begin{array}{r}\text { (MP) medium productive }- \\
16.6-21.1 \mathrm{tha}^{-1}\end{array}$ & Mriya \\
\hline 3. & $\begin{array}{r}\text { (BP) biologically highly } \\
\text { productive }-21.2-25.7 \mathrm{t} \mathrm{ha}^{-1}\end{array}$ & Lovage \\
\hline 4. & $\begin{array}{r}\text { (HP) highly productive }- \\
25.8 \text { and higher } \mathrm{tha}^{-1}\end{array}$ & K-3, Redei, MLL \\
\hline
\end{tabular}

Table 3. Ecological flexibility of the lovage samples on average during 2014-2016.

\begin{tabular}{|l|l|c|c|c|c|c|c|}
\hline \multirow{2}{*}{$№$} & \multirow{2}{*}{$\begin{array}{c}\text { Name of } \\
\text { the } \\
\text { sample }\end{array}$} & \multicolumn{2}{|c|}{ Green mass output per plant } & \multicolumn{3}{|c|}{ Green mass productivity } \\
\cline { 3 - 9 } & $\mathrm{X}$ avg, & $\mathrm{bi}$ & $\mathrm{Vi}$ & $\begin{array}{c}\mathrm{X} \text { avg, kg } \\
\text { ha-1 }\end{array}$ & $\mathrm{bi}$ & $\mathrm{V}_{\mathrm{i}}$ \\
\hline 1. & Mriya (St) & $304.13+25.67$ & 0.40 & -36.12 & $12.17+1.02$ & 0.40 & -1.44 \\
\hline 2. & Lovage & $289.30+15.00$ & 0.23 & -50.95 & $11.57+0.62$ & 0.24 & -2.04 \\
\hline 3. & MLL & $300.57+19.72$ & 0.31 & -39.69 & $12.03+0.78$ & 0.31 & -1.58 \\
\hline 4. & Redei & $377.33+96.86$ & 1.51 & 37.08 & $15.10+3.85$ & 1.50 & 1.49 \\
\hline 5. & K-3 & $426.07+172.25$ & 2.68 & 85.81 & $17.03+6.88$ & 2.68 & 3.42 \\
\hline 6. & KJ & $372.10+92.95$ & 1,45 & 31.85 & $14.87+3.72$ & 1.45 & 1.26 \\
\hline 7. & Coral & $312.27+27.49$ & 0,43 & -27.99 & $12.50+1.10$ & 0.43 & -1.11 \\
\hline
\end{tabular}

During the period of investigations in 2011-2016 the bushes of lovage formed standard seeds, the mass of which fluctuated from $14.7 \mathrm{~g}$ to $21.7 \mathrm{~g}$ per plant, and the mass of 1000 seeds was between 2.6 and $6.0 \mathrm{~g}$.

The results of the research of the influence of meteorological factors on lovage seeds productivity are shown on Figure 4-5.

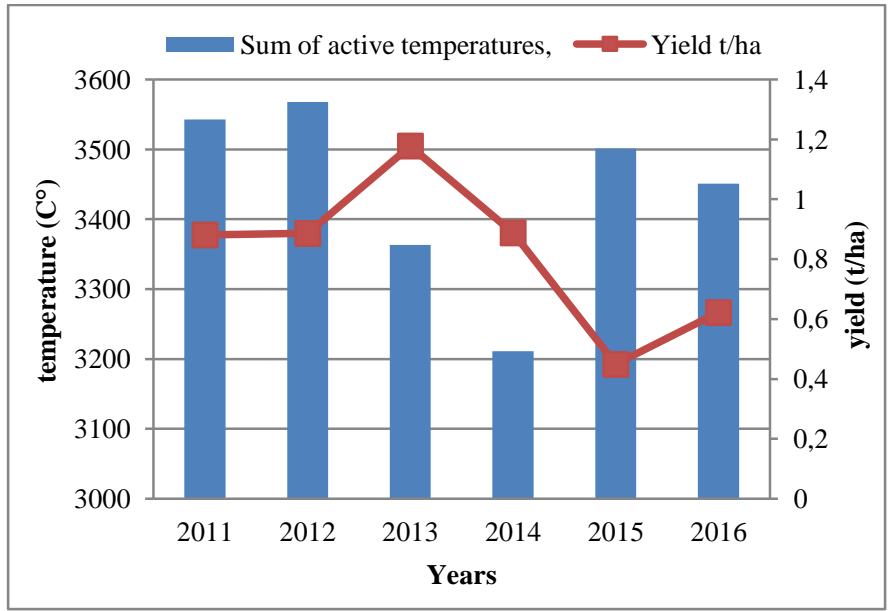

Figure 4. Dependence of the lovage seeds productivity on the sum of active temperatures during the vegetation periods of 2011-2016.

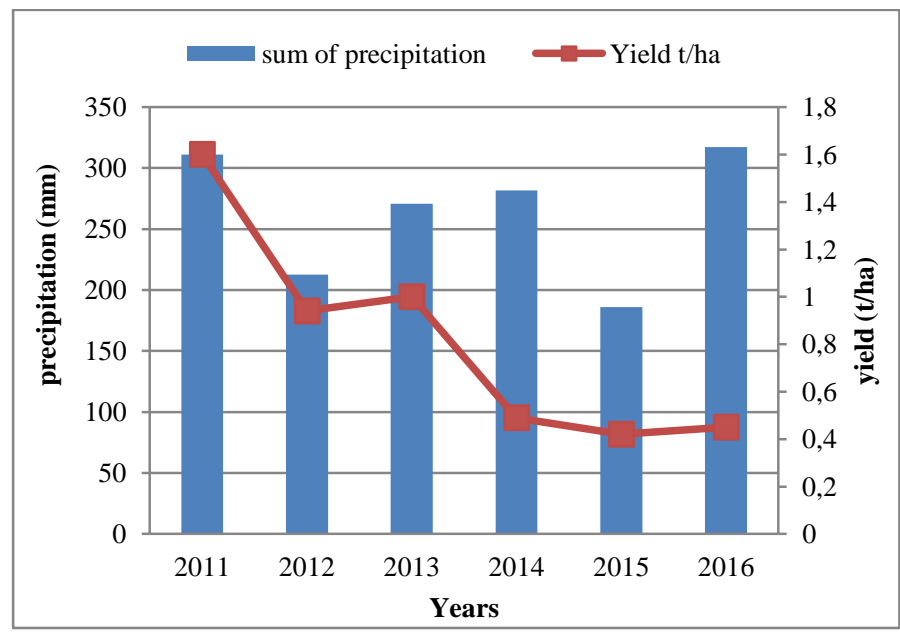

Figure 5. Formation of the lovage seeds productivity depending on the sum of precipitation during the vegetation periods of 2011-2016.

The productivity of the lovage seeds during the years 20112016 fluctuated between 0.43 (2015) and 1.6 (2011) $\mathrm{t} \mathrm{ha}^{-1}$, variation coefficient was 55.32, which means that during the years the productivity essentially varied. According to the data of the statistic calculations, the coefficient of variation according to the sum of the active temperatures was low and reached $3.88 \%$, according to the amount of the precipitation $20.19 \%$, which proves the working hypothesis on the insufficient influence of the limiting factors on seed productivity (coefficient of correlation according to the sum of active temperatures $\mathrm{r}=0.42$, according to the amount of precipitation $\mathrm{r}=0.30$ ).

Dependence of the seed productivity on the hydrothermal coefficient during the vegetation period is described by the equation of regression: $\mathrm{Y}=-9.2651+28.5921 \mathrm{x}-19.4012 \mathrm{x}^{\mathrm{A}} 2$ (Figure 6).

Determination coefficient is insufficient $\left(\mathrm{R}^{2}=0.30\right)$, and the coefficient of the multiple correlation is medium $(\mathrm{R}=0.55)$, which shows the average percentage of possibility of the use of the given equation for the definition of the productivity level.

Selection plays an important role in the increase of the lovage seed productivity. The success of obtaining positive results depends on the correctly chosen source material and creation of new, hopefully highly productive varieties on its basis. 


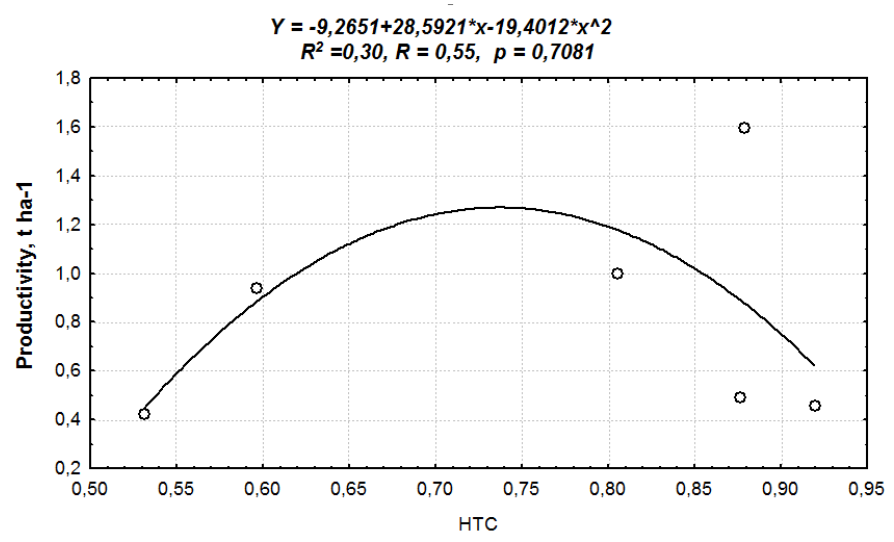

Figure 6. Influence of HTC on the lovage seed productivity (2011-2016).

During 2011-2016 we had singled out the samples with high seed productivity. MLL sample exceeded due to its amount of blooming plants $(62.5 \%)$ and the seeds yield per $\mathrm{m}^{2}$ - $86.7 \mathrm{~g}$, (21.7 $\mathrm{g}$ from each plant) the standard - Mriya variety, which had $50.0 \%$ of blooming plants and the seeds yield reached $76.8 \mathrm{~g} / \mathrm{m}^{2}$ (19.2 $\mathrm{g}$ from each plant). The Redei variety did not exceed the standard according to the amount of blooming plants (37.5\%), but exceeded it according to the yield of seeds per plant, which reached $19.9 \mathrm{~g}$, and the weight of 1000 seeds was 6 g. Seed similarity reached $88 \%$ and was the highest during the whole period of the research.

The important characteristics of the sample's value are its reaction to the fluctuation of the limiting factors, which is evaluated by the coefficient of ecological flexibility. The bigger this coefficient, the more sensitive the sample is to the change of the environmental factors. As we see from Table 4, the least sensitive to the change of ecological factors is the sample of the local population KJ, the indicator of flexibility coefficient is close to $0(0.36)$ and the coefficient of variation is negative (-0.01); this means that this sample has stable yield of the seed mass and productivity per plant, and the influence of the weather conditions is minimal.

Table 4. Ecological adaptive ability of the lovage samples according to the seed weight in average during 2014-2016.

\begin{tabular}{|c|c|c|c|c|c|c|c|}
\hline \multirow[b]{2}{*}{ № } & \multirow{2}{*}{$\begin{array}{c}\text { Name of } \\
\text { sample }\end{array}$} & \multicolumn{3}{|c|}{ Seed weight per plant } & \multicolumn{3}{|c|}{ Seed productivity } \\
\hline & & $\begin{array}{c}\mathrm{X} \text { avg, } \\
\mathrm{g}\end{array}$ & bi & $\mathrm{Vi}$ & $\begin{array}{c}\mathrm{X} \text { avg, } \\
\mathrm{kg} / \mathrm{ha}\end{array}$ & bi & $\mathrm{Vi}$ \\
\hline 1 & Mriya (St) & 11.70 & 3.55 & 0.19 & 468.00 & 3.55 & 7.43 \\
\hline 2 & Lovage & 10.50 & 1.27 & -1.01 & 420.00 & 1.27 & -40.57 \\
\hline 3 & MLL & 12.40 & 3.47 & 0.89 & 496.00 & 3.47 & 35.43 \\
\hline 4 & Redei & 10.83 & 2.45 & -0.68 & 433.33 & 2.45 & -27.24 \\
\hline 5 & $\kappa-3$ & 11.63 & 2.99 & 0.12 & 465.33 & 2.99 & 4.76 \\
\hline 6 & КJ & 11.50 & 0.36 & -0.01 & 460.00 & 0.36 & -0.57 \\
\hline 7 & Coral & 12.03 & 2.98 & 0.52 & 481.33 & 2.98 & 20.76 \\
\hline
\end{tabular}

Of all the samples of foreign selection Lovage (Poland) reacts to the changes of growing conditions the least of all. The average weight of the seeds per plant reaches $10.5 \mathrm{~g}$ during the period of 2014-2016 and is the lowest among the samples; the coefficient of flexibility is 1.27 , which shows the essential influence of weather conditions on seed formation (bi=1.27) and productivity $(\mathrm{bi}=1.27)$. We should mention that this sample has the negative coefficient of variation $-1.01 \%$ and $-40.57 \%$.

An important indicator of the quality of plant raw material is the content of biologically active substances that give the plants the properties necessary for the plants to be used in the food and other industries. The results of the study of the outcome of lovage essential oils and the influence of the abiotic factors on the mass fraction of oil are significantly different in various authors (Bylaite et al., 1998; Raal et al., 2008; Korablyova, 2011).

According to the results of our studies, the accumulation of dry matter in the leaves (commodity raw materials) of the lovage samples varied from $16.2 \%(\mathrm{~K}-3)$ to $23.0 \%(\mathrm{KJ})$, more ascorbic acid was found in the MLL sample: $32.3 \mathrm{mg} / 100 \mathrm{~g}$ and in $\mathrm{KJ}: 26.0 \mathrm{mg} / 100 \mathrm{~g}$, the lowest concentration was found the varieties of foreign selection: Lovage and Redei, where it was 16.3 and $21.2 \mathrm{mg} / 100 \mathrm{~g}$ respectively. The mass fraction of essential oil in the leaves fluctuated within the range of $0.16-$ $0.28 \%$ of the raw mass weight. Significant yield of essential oils was observed in samples MLL: $0.28 \%$ or $0.93 \%$ from completely dry substance (c.d.s.), and KJ: $0.22 \%$ or $0.80 \%$ from c.d.s.

Varieties with a green and dark green leaf coloring (Lovage, MLL and Redei) were shown (via laboratory method and visual assessment) to have a high coefficient of drought resistance (Table 5) during the critical period with high temperatures.

Table 5. Dependence of green mass productivity on the features of drought resistance of lovage samples in the years with different levels of moisture supply.

\begin{tabular}{|l|c|c|c|c|}
\hline \multirow{2}{*}{$\begin{array}{l}\text { Characteristics of } \\
\text { drought resistance }\end{array}$} & \multicolumn{4}{|c|}{ Drought resistance coefficient } \\
\cline { 2 - 5 } & $\mathrm{r}$ & $\mathrm{r}(\mathrm{lim})$ & $\mathrm{r}$ & $\mathrm{r}(\mathrm{lim})$ \\
\hline & 0.83 & $0.64-0.93$ & 0.91 & $0.87-0.97$ \\
\hline Growth intensity & 0.64 & $0.41-0.76$ & 0.75 & $0.54-0.83$ \\
\hline Length of the leaf & 0.48 & $0.41-0.65$ & 0.67 & $0.56-0.89$ \\
\hline Width of the leaf & 0.28 & $0.21-0.35$ & 0.14 & $0.23-0.38$ \\
\hline $\begin{array}{l}\text { Water-keeping } \\
\text { ability }\end{array}$ & 0.35 & $0.28-0.43$ & 0.16 & $0.07-0.16$ \\
\hline $\begin{array}{l}\text { Resistance to } \\
\text { dehydration }\end{array}$ & 0.30 & $0.27-0.32$ & 0.67 & $0.52-0.75$ \\
\hline $\begin{array}{l}\text { Ability to reutilize } \\
\text { in arid conditions }\end{array}$ & 0.76 & $0.66-0.85$ & 0.77 & $0.67-0.87$ \\
\hline Height of the plant & & & & \\
\hline
\end{tabular}

The above mentioned varieties have a high water retention index, but different levels of water-keeping. The results of the conducted research showed that the highest indexes of the coefficient of drought resistance and water retention were observed in the early and middle-ripen varieties. Using the method of multiple correlation analysis we identified the main signs of drought resistance, which are responsible for the formation of productivity at different levels of moisture content. The determinant factors for lovage are the intensity of plant growth in the initial period of development, the height of the plant, which correlates with the formation of a powerful root system $(r=0.830 .91, r=0.760 .77)$ and the size of leaves both during dry and wet years.

When creating the lovage varieties one should pay attention to the complex of biological, genetic and economic features that manifest themselves in one genotype. An important aspect in selection is the fixation of the highest minimum productivity level in the conditions of rapidly changing agro-climatic factors. Performance parameters may vary depending on environmental factors, technological support and the genetic potential of the culture. In the course of the research we established the main indicators of the valuable signs of the productivity of lovage and their optimal parameters for creating 
a model of a variety with a more complete and effective disclosure of the potential productivity (Table 6).

Table 6. Basic indicators and optimal parameters of the model variety of lovage

\begin{tabular}{|l|c|}
\hline Indicators & Parameters \\
\hline Period of sprouting/growth - mass bushing, days & $27.5 \pm 2.5$ \\
\hline Height of the plant, cm & $80 \pm 4.3$ \\
\hline Diameter of the plant, cm & $62.5 \pm 3.7$ \\
\hline Stems amount, pieces & $26 \pm 4.0$ \\
\hline Length of the leaf, cm & $12 \pm 1.2$ \\
\hline Width of the leaf, cm & $8.1 \pm 0.6$ \\
\hline Commodity raw material output (leaves), $\%$ & $55 \pm 5.0$ \\
\hline Potential productivity, tha ${ }^{-1}$ & $26.5 \pm 2.5$ \\
\hline Output of the essential oil, $\%$ of the raw mass & $0.26 \pm 0.2$ \\
\hline
\end{tabular}

\section{Conclusions}

The results of the studies presented in the article indicate the high ecological flexibility of the samples of lovage output material, the high biological potential of the resulting high quality commodity raw materials, which makes it possible to grow it in Transcarpathia. The value of this culture for Transcarpathia lies in the unpretentiousness to the conditions of cultivation and the ability to grow on soils (heavy, low humus content, low in nutrients) unsuitable for growing basic vegetable and green crops, as well as the possibility of filling a new niche of spicy vegetable crops on the market of the given region. The perspective of growing lovage in the given region is conditioned by a wide range of use of this useful plant in the food, canning, pharmaceutical, perfumery, cosmetic and other industries.

\section{References}

Allard, R. W. (1963): Seasonal variability of recombination frequency in lima bean //Geneties. 48. p. 1389-1395.

Azzi, J. (1959): Agricultural ecology / J. Azzi; tr. From Eng.M. : Foreign literature publishing house, 1959. - 477 p.

Bodmer, W. F. (1962): Recombination variability as the result of violation of development channeling // Adv. Genet/11. p. 1100 .

Brounov, P. I. (1957): Agrarian meteorology / P.I. BrounovM.: Hydrometpub, - V.2. -338 p.

Bylaite, E., Venskutonis, R. P., Roozen, J. P. (1998): Influence of Harvesting Time on the Composition of Volatile Components Different Anatomical Parts of Lovage (Levisticum officinale Koch). Journal of Agricultural Food Chemistry 46(9). p. 3735-3740.

Cherevchenko, T. M., Rakhmetov, D. B., Haponenko, M. B. (2012): Preserving and enrichment of the plant resources by means of introduction, selection and biotechnology: monography. K.: Phytosociocentre, p. 9-10.

Derzhypilskiy, L. M. (2006): Medicinal plant growing and berry-growing. Kosiv: Pysanyi kamin, p. 17-19.

Dospekhov, B. A. (1985): Methodology of field experiments. M.: Kolos, 351 p.

Dragavtzev, V. A., Averianova, A. F. (1983): Mechanisms of collaboration of genotype-environment and homeostasis of the qualitative plants' characteristics //Genetics, T. 19. № 11. p. 1806-1810.

Korablyova, O. A. (2011): Spices and seasoning. K.: Univest Media, p. 97-99.

Korablyova, O. A. (2012): Useful plants in Ukraine, from introduction to usage. Monography K.: Phytosociocentre, p. 910 .

Kormosh, S. M., Leonova, O. M. (2007): Methods of conducting the expert assessment of lovage varieties (Levisticum officinalis C. Koch.) on the difference, homogeneity and stability. Protection of rights of plant varieties. Official Bulletin, Methodology. P. 3, № 2. p. 167176.

Lu, B. C., Chiu, S. M. (1976): Genetic recombination in Copsinus V. Repair syntesis of deoxyribonycleic acid and its relation to meiotic recombination // Mol. And Gen. Genet. 147, 2. p. 121-127.

Ludilov, V. A. (1987): Seed production of vegetable and melon crops / V. A. Ludilov. - M.:Agropublishing, - 224 c.

Nazarenko, L. G. (2008): Aromatic plants of Southern Ukraine. Symferopol: Tavria, 144 p.

Orliyk, A. P., Goncharova, K. V. (2003): Problem of combination of high productivity and ecological sustainability of the winter wheat sorts. K.: Agrarian science, p. 180-187.

Rakhmetov, D. B. (2016): Introduction of new and low spread medicinal plants in Ukraine / D.B.Rakhmetov, S.M.Kalevska, S.O.Rakhmetov // Medicinal plants: traditions and perspectives of research: materials III intern. conf., dedicated to the 100 year Experimental station of medicinal plants, Berezotecha, 1415 July 2016 y. - Berezotocha, p. 71-73.

Sheludko, L. P., Kutzenko, N. I. (2013): Medicinal plants (selection and seeds production) Poltava, $476 \mathrm{p}$.

Sichkar, V., Ganzhelo, O., Lavrova, G. (2013): Increase of the adaptive ability of soy in the drought conditions as a basic direction of modern selection in Southern Ukraine. Lviv national agrarian university annual. Agronomy. Lviv. Nat. Agr. Uni., № 17 (2). p. 187.

Zhuchenko, A. A. (1988): Adaptive potential of the cultural crops. Kyshinyov: Shtiintsa, 767. p.

Internet 1: www.internet.tdmu.edu.ua 